\title{
Exploring the Effectiveness of Faculty Development Program on Medical and Health Related Sciences Education
}

\author{
Amira S. Alsagheer ${ }^{1,2^{*}}$, Fatma M. Ghoneim ${ }^{3}$ and Heba Mohtady Ali4,5 \\ 'Medical Education Department, Faculty of Medicine, Suez Canal University, Egypt; dr.asa84@yahoo.com \\ ${ }^{2}$ Medical Education Department, Fakeeh College for Medical Sciences, Jeddah - KSA \\ ${ }^{3}$ Staff Development Unit, Fakeeh College for Medical Sciences, Jeddah - KSA \\ ${ }^{4}$ Cities Research Institute, Griffith University, Australia \\ ${ }^{5}$ Faculty of Medicine, Zagazig University, Egypt
}

\begin{abstract}
The professional development of faculty is progressively noticeable in both higher and health profession education. The monitoring of faculty development activities could enhance their effectiveness and contribute to the education quality. This study aimed to address a faculty development program regarding four active learning-based approaches and their impact on three undergraduate medical and health-related programs. Methods: Following the implementation of the faculty development program, it was evaluated based on the first three levels of Kirkpatrick's Model. The program development was underpinned by the training needs assessment of the faculty. Results: The results of the evaluation using the Kirkpatrick model (reaction, learning, behaviour, and actions) were informative. The response rate by faculty was $100 \%$. Overall, faculty satisfaction with their development activities (Kirkpatrick $1^{\text {st }}$ level) was $91 \%$. The results of the T-tests of the Faculty Development Programs (FDPs) were statistically significant $(\mathrm{p}<0.05)$. The gain and transfer of knowledge in the workplace were ensured. Discussion and Conclusion: This research provided valuable information regarding the impact of faculty development activities on the faculty from various perspectives. The current study endorses the faculty development program's positive impact on the performance of the faculty, teaching effectiveness, and increased the increased student satisfaction about active learning-based teaching.
\end{abstract}

Keywords: Active Learning, Faculty Development, Monitoring, Professional Development

\section{Introduction}

In higher education, change becomes a ceaseless phenomenon ${ }^{1}$. Several global changes led to numerous challenges affecting the academics' performance effectiveness. Faculty need to cope with these challenges, to ensure their best teaching standards ${ }^{2,3}$.

Active learning-based approaches help Students, as adult learners, actively engage, critically think, and successfully achieve their learning outcomes ${ }^{4,5}$. These approaches include interactive lectures, Small-group discussions, Flipped Classes $^{6,7}$, Team-Based Learning (TBL), and Problem-Based Learning $(\mathrm{PBL})^{8}$. Researchers are progressively investigating factors associated with teaching quality to improve student achievement ${ }^{9}$.

In health professional schools, the faculty, who are holders of degrees that necessitated years of experience in the specific content area, often lack the evidence-based teaching knowledge and skills ${ }^{10,11}$. Hence, there are genuine inquiries for faculty development programs to foster teaching quality and improve the educators' performance ${ }^{12,13}$.

Faculty Development Programs (FDPs) described a range of planned and carried out activities that upgrade the faculty's professional teaching, research, and management skills ${ }^{14}$. However, many challenges still hinder staff development program's success ${ }^{15}$. An in-depth understanding of FDPs would reinforce authentic professional development and provide a piece of evidence for how teachers might change via these activities ${ }^{16}$. The purpose of this study was to address the faculty development program regarding four active learningbased approaches and their impact on various undergraduate medical and health-related programs (Medicine, Nursing, and Medical Laboratory Sciences).

\footnotetext{
${ }^{*}$ Author for correspondence
} 


\section{Materials and Methods}

In a private higher education institution for medical sciences in Saudi Arabia, the Staff Development Unit (SDU) as a part of the Medical Education Department supported the faculty in confronting the evolving higher education challenges. SDU develops a comprehensive yearly FDP to enhance their professional skills in various perspectives. The program was mainly hybrid, highly interactive, based on active learning principles, and implemented by senior and experienced medical educationists. This program aims to encourage staff to improve their job performance through implementing new teaching strategies that address different learning domains, Enhance the capability of staff to engage in research and community activities, Support staff to improve their competencies, and Enable staff to contribute effectively to the achieving of the college's strategic priorities.

\subsection{First: Phases of Development of a Staff Development Program}

\subsubsection{Pre-Training Phase (Planning)}

The staff development unit assessed and identified the learning and development needs of the staff in the beginning of each academic year.

Problem identification, problem analysis, and Training Needs Analysis (TNA) are useful in the assessment of organizations' training needs. This was based on gap analysis (the gap between the knowledge, skills, and attitudes that the people in the organization currently possess and the knowledge, skills, and attitudes that they require to meet the organization's objectives). The Staff Development Unit conducted TNA through organizational analysis, job or task analysis, and target-group analysis.

Planning and designing of training programs include:

- Formulation of learning goals.

- Formulation of testing and evaluation criteria.

- Program development.

Therefore, the Staff Development Unit assessed and identified the learning and development needs of the academic and administrative staff at the beginning of each academic year through staff survey to:

- Identify the areas for faculty development (e.g., teaching and learning, assessment, mentoring, research, leadership and personal development skills).

- Address development areas required by administrative staff (e.g., time management, meeting management and team building).
- Categorize the target audiences (e.g., junior faculty members, all faculty levels, preceptors, instructors and other employees).

- Assign trainers/instructors for each training program as per their qualifications interests and expertise.

- The final program is submitted to the College Council for approval, and then it will be circulated to all staff.

- Media and public relations unit is responsible for the organization, and the announcement of the activity.

- A flyer is developed by the media and public relations unit and will be distributed to all FCMS departments two weeks before the event.

\subsubsection{Training Phase (Implementation)}

The implementation of the activities is arranged by the supervisor of the staff development unit. Attendance record and documentation for each activity was prepared by the planner of the activity, and to be submitted to the supervisor of the staff development unit.

\subsubsection{Post-Training Phase (Evaluation)}

In this phase, the impact of the faculty development program is measured and evaluated through program evaluation, impact assessment, implementation, and transfer of learning outcomes and follow-up. Evaluation of any training programs is conducted according to Kirkpatrick's Four Levels of Evaluation:

Level 1 Evaluation (Reactions): this level measures how participants react to the training program. The participants are asked to answer questions regarding their perceptions. Level 2 Evaluation (Learning): this level determines the amount of learning that has occurred. Participants take the test or assessment before the training (pre-test) and after training (post-test).

Level 3 Evaluation (Transfer): this level measures the transfer that has occurred in learners' behaviour due to the training program. As described by personal evaluation reports, peer evaluations of teaching and evaluation reports focused on one or more aspects of faculty effectiveness.

Level 4 Evaluation (Results): at this level, the final results of the training are assessed and analyzed. These include outcomes that the organizations have determined to be good. This analysis is multifaceted and needs to be agreed upon early in the process of developing a program impact on teaching. For instance, the number of courses changed the number of activities initiated, changes in course evaluations, and impact on learning (e.g., student retention, grade point averages). 


\subsection{Second: Research Designs}

The design selected for this research study was quantitative in nature using a Satisfaction survey, Pre and post-test, and Identification of the percentage of implemented studentcentered teaching strategies.

\subsection{Third: Data Collection and Analysis}

The data collection techniques used in this study consisted of surveys, tests, and documentation reviews. These documents included study guides, course specifications, and teaching materials. Most of the documents received from the participants were soft copies from each participant's course.

Data collection and analysis were conducted according to Kirkpatrick's Levels of Evaluation ${ }^{21}$ as follow:

The first evaluation level gauged participants' reactions to the program, using survey questions regarding their perceptions about the content, Resources, and venue of the workshop, and speakers on a Likert scale from 1-5 (1 strongly disagree - 5 strongly agrees).

The instrument used for this level is 15 items evaluation survey with a Likert scale ( 5 strongly agree - 1 strongly disagree).

The second evaluation level assessed the learning and knowledge acquisition using Pre-\& Post-tests and assignments.

The third evaluation level determined the transfer occurrence in learners' behaviour due to their professional development and training with the following evidence of transfer and application. The medical education department generated monitoring worksheets. These worksheets demonstrated the percentage of all teaching strategies in each course in each of the three programs through documentation review. All faculty teaching in the three programs were requested to complete documents and study guides for the teaching strategies' proportions in their courses. The study used a percentage of different interactive teaching strategies implementation in all courses to measure knowledge transfer to the workplace

In addition to that, the study used the course evaluation survey and teaching effectiveness questionnaires as evidence of knowledge transfer to real situations. Students filled these questionnaires to measure their satisfaction with teaching. The questionnaire is 20 items evaluation survey with a Likert scale from 1-5 (5 strongly agree - 1 strongly disagree), where the students evaluate instructor teaching skills. Another questionnaire with a Likert scale from 1-5 (5 strongly agree-1 strongly disagree) is the course evaluation questionnaire that includes five factors which are course orientation, faculty, educational resources, Assessment process, and Course Learning Outcomes (CLOs) achievement.

\subsection{Fourth: Sampling and Sample Size}

Participants: The sample for this research study were thirtysix Ph.D. holder academic staff in different programs in FCMS (Nursing Program, Medical Laboratory Sciences Program, and Bachelor of Medicine Bachelor of Surgery Program). The participants attended all SDU workshops related to studentcentered teaching strategies.

\subsection{Sampling}

The sample was a comprehensive convenient sample.

\section{Results}

FCMS faculty were interested in completing all the required questionnaires, pre-test and post-tests, as evidenced by the response rate of $100 \%$. The number of participants was thirtysix Ph.D. holder academic staff in different programs in FCMS (Nursing Program, Medical Laboratory Sciences Program, and Bachelor of Medicine Bachelor of Surgery program (MBBS)) as shown in Table 1 .

Table 1. Number and ranking of participants in each program

\begin{tabular}{|c|c|c|c|c|c|c|c|c|c|}
\hline \multicolumn{9}{|c|}{ Number of participants (36 PhD) } & College \\
\hline \multicolumn{3}{|c|}{$\begin{array}{c}\text { MBBS program } \\
(14)\end{array}$} & \multicolumn{3}{|c|}{$\begin{array}{c}\text { MLS program } \\
\text { (10) }\end{array}$} & \multicolumn{3}{|c|}{$\begin{array}{c}\text { Nursing program } \\
\text { (12) }\end{array}$} & \multirow{6}{*}{$\begin{array}{c}\text { Fakeeh } \\
\text { College } \\
\text { for } \\
\text { Medical } \\
\text { Sciences } \\
\text { (FCMS) }\end{array}$} \\
\hline Males & \multicolumn{2}{|c|}{ Females } & Males & \multicolumn{2}{|c|}{ Females } & Males & \multicolumn{2}{|c|}{ Females } & \\
\hline 6 & \multicolumn{2}{|c|}{8} & 5 & \multicolumn{2}{|c|}{5} & 7 & \multicolumn{2}{|c|}{5} & \\
\hline \multicolumn{3}{|c|}{$\begin{array}{c}\text { MBBS program } \\
(14)\end{array}$} & \multicolumn{3}{|c|}{$\begin{array}{c}\text { MLS program } \\
\text { (10) }\end{array}$} & \multicolumn{3}{|c|}{$\begin{array}{c}\text { Nursing program } \\
\text { (12) }\end{array}$} & \\
\hline Prof. & $\begin{array}{c}\text { Assoc. } \\
\text { Prof. }\end{array}$ & $\begin{array}{l}\text { Asst. } \\
\text { Prof. }\end{array}$ & Prof. & $\begin{array}{l}\text { Assoc. } \\
\text { Prof. }\end{array}$ & $\begin{array}{l}\text { Asst. } \\
\text { Prof. }\end{array}$ & Prof. & $\begin{array}{l}\text { Assoc. } \\
\text { Prof. }\end{array}$ & $\begin{array}{l}\text { Asst. } \\
\text { Prof. }\end{array}$ & \\
\hline 2 & 5 & 7 & 2 & 4 & 4 & 2 & 2 & 8 & \\
\hline
\end{tabular}

The Kirkpatrick model's first evaluation level (reaction) revealed that the participants' satisfaction was excellent as all the workshops' evaluation survey results were above 4 out of 5. The overall scores are 4.4 for Team-Based Learning (TBL) and this was distributed as follows: the first factor that was related to the speaker scored 4.2. And the content factor score was 4.4 and the score of resources and the venue was 4.5. Also, the overall of the Problem-Based Learning (PBL) workshop evaluation survey was 4.7 and as shown in table one the highest score in this evaluation survey was for the speaker however for effective teaching strategies, the highest score factor was the program content and the overall score was 4.6. In addition to that the Flipped classes workshop evaluation survey score was 4.6 (Table 2). 
Table 2. The first evaluation level scores of the provided workshop sessions

\begin{tabular}{|l|c|c|c|c|}
\hline & $\begin{array}{c}\text { The } \\
\text { Speaker }\end{array}$ & $\begin{array}{c}\text { The } \\
\text { program } \\
\text { content }\end{array}$ & $\begin{array}{c}\text { The venue } \\
\text { and } \\
\text { resources }\end{array}$ & Overall \\
\hline TBL workshop & 4.2 & 4.4 & 4.5 & 4.4 \\
\hline PBL workshop & 4.9 & 4.7 & 4.3 & 4.7 \\
\hline $\begin{array}{l}\text { Flipped classes } \\
\text { workshop }\end{array}$ & 4.7 & 4.6 & 4.6 & 4.6 \\
\hline $\begin{array}{l}\text { Effective } \\
\text { teaching } \\
\text { strategies }\end{array}$ & 4.7 & 4.8 & 4.6 & 4.7 \\
\hline
\end{tabular}

* participants rated scores of the 15 items of the workshop evaluation survey. The Scale (5 strongly agree - 1 strongly disagree).

The Kirkpatrick model's $2^{\text {nd }}$ evaluation level (Learning): Pre- and Post-tests and assignments were distributed to faculty staff before and after all workshops. The results of the T-tests of the FDPs were statistically significant $(\mathrm{p}<0.05)$.

The results showed that the three workshops' T-tests were statistically significant, and these results indicated an improvement in faculty's knowledge after workshop conduction (Table 3).

For the $3^{\text {rd }}$ evaluation level (behaviour and actions), the monitoring worksheets indicated that all the instructors used the new interactive teaching strategies, which ensured the transfer of the knowledge in the workplace. These adopted new teaching strategies were reported in their study guides and documents. The teaching effectiveness survey and course evaluation survey indicated a high degree of students' satisfaction regarding staff teaching skills and their usages of various teaching strategies in all three programs.

The percentage of flipped classes' implementation in the Medicine program was $25 \%$ however it was lower in MLS and Nursing program to be $15 \%$ and $20 \%$, respectively. Also, the TBL implementation percentage was equal in all three programs, and it was $25 \%$. However, PBL implementation was $25 \%$ only in the MBBS program. In addition to that, the average score for the teaching effectiveness survey were 4.3 in the Medical Laboratory Sciences (MLS) program, 4.8 in the Medicine program and 4.6 in the Nursing program. Also, the average score in the Course Evaluation Survey in the Medicine program was 4.6 and 4.5 in both MLS and Nursing programs (Table 4).

Table 4. The third evaluation level scores (evidence of knowledge transfer to students)

\begin{tabular}{|l|c|c|c|}
\hline Survey & MBBS & MLS & Nursing \\
\hline $\begin{array}{l}\text { *Teaching } \\
\text { effectiveness survey }\end{array}$ & 4.8 & 4.3 & 4.6 \\
\hline $\begin{array}{l}\text { *Course Evaluation } \\
\text { Survey }\end{array}$ & 4.6 & 4.5 & 4.5 \\
\hline $\begin{array}{l}\text { Percentage of different interactive teaching strategies } \\
\text { implementation in all courses }\end{array}$ \\
\hline Flipped classes & $25 \%$ & $15 \%$ & $20 \%$ \\
\hline PBL & $25 \%$ & $0 \%$ & $0 \%$ \\
\hline TBL & $25 \%$ & $25 \%$ & $25 \%$ \\
\hline
\end{tabular}

\section{Discussion}

The faculty development program at Fakeeh College for Medical Sciences was evaluated for its effectiveness according to the first three- Kirkpatrick levels (reaction, learning, behaviour, and actions). In the First level (Reaction level), the participants expressed high satisfaction in the immediate feedback after the FDPs implementation. This level also included measuring participants' reactions or attitudes toward the program's specific components, such as the speakers, the workshop content, the venue, and the workshop's overall evaluation. The excellent reaction results in this level were underpinned by two key factors. The first factor was that the program was based on the faculty training needs assessment. Such assessment is crucial to realize the educators' requirements and perceptions before applying new education methods and before creating these programs ${ }^{17}$. The second factor was that our FDPs were given by experienced medical educationists, as role models, who adopted interactive strategies and active

Table 3. The knowledge acquisition by faculty staff

\begin{tabular}{|c|c|c|c|c|c|c|c|}
\hline & & \multirow[t]{2}{*}{$\mathbf{t}$} & \multirow[t]{2}{*}{ df } & \multirow[t]{2}{*}{ Sig. (2-tailed) } & \multirow{2}{*}{$\begin{array}{c}\text { Mean } \\
\text { Difference }\end{array}$} & \multicolumn{2}{|c|}{$\begin{array}{c}\text { 95\% Confidence Interval of the } \\
\text { Difference }\end{array}$} \\
\hline & & & & & & Lower & Upper \\
\hline PBL workshop & Post-test scores & 9.467 & 35 & 0.000 & 4.61538 & 3.5532 & 5.6776 \\
\hline TBL workshop & Pre-test scores & 7.359 & 35 & .000 & 3.30000 & 2.2855 & 4.3145 \\
\hline $\begin{array}{l}\text { Flipped classes } \\
\text { workshop }\end{array}$ & Post-test scores & 14.351 & 35 & .000 & 3.38462 & 2.8989 & 3.8703 \\
\hline
\end{tabular}


learning-based approaches. More experienced faculty can perform as innovation models towards teaching change ${ }^{18}$. Health professions' education enhancement depends on role-modelling and faculty development ${ }^{19}$. Thus, the faculty perceived training as more creative and innovative ${ }^{20}$.

Regarding the second Level (learning level), it included evaluating the faculty's assignments or comparing their preand post-test results. This level showed increased relevant knowledge following our FDPs. The faculty gained the required knowledge to apply the new and interactive teaching strategies they were trained about. The pre- and post-test comparison aimed to document the changes made due to participating in the $\mathrm{FDP}^{10}$. Our results were similar to a study conducted in the School of Medicine, Marmara University, Istanbul, Turkey, where they evaluated their faculty development training program $^{11}$.

The final step in our study is the third level of the Kirkpatrick Model (behaviour and action). It is about monitoring actual behaviours demonstrated by the faculty staff after training in the workplace. According to the results, the trained instructors used the new and interactive teaching strategies, which ensured the transfer of knowledge in the workplace. The analysis results showed that the students were satisfied with the instructor's teaching style and skills and the course itself. The professional and academic development of an institution's faculty members significantly affects its capacity and educational achievements ${ }^{12}$. FDPs "are powerful organizational mechanisms that can engender the change we need in the academic culture towards recognizing teaching and learning as valuable and worthwhile activities" $^{20}$.

Similar to our results, in FDPs developed to improve dental faculty's didactic skills, several faculty members reported that these programs helped them in creating an active and communicative learning environment that gained their students' satisfaction ${ }^{21}$.

Also, our results were consistent with a study conducted in Harvard Medical School, USA, and aimed at identifying the long-term effects of a professional development program on physician educators ${ }^{19}$.

The current study results generally confirm the positive impact of FDPs on faculty's performance and students' perception. Similarly, Sarikaya et al. $(2010)^{11}$ reported how teachers who attended the workshop-based courses had improved their teaching and assessment methods. The teachers' improvement is evident in interactive teaching, demonstration, coaching, and mentoring. Such improvement was reflected in the students' perception and achievements ${ }^{11}$. The teaching appreciation via funding, time, information, and faculty development initiatives could positively influence the organizational change and improvement ${ }^{8}$.

\section{Conclusions}

The current study highlights the faculty development program's positive impact on the performance of the faculty and teaching effectiveness. Additionally, FDPs fostered active learning-based teaching strategies and increased student satisfaction about teaching. Our findings can direct the development of similar FDPs at other Higher education institutions, in particular in the health profession education sector.

\section{References}

1. Bond MA, Blevins SJ. Using faculty professional development to foster organizational change. A Social Learning Framework. 2020; 64:229-237. https://doi.org/10.1007/s11528-019-00459-2.

2. Dhanpat N, Geldenhuys M, De Braine R. Preliminary development of the higher education Hindrance. Demands Scale amongst academics in the South African context. SA Journal of Industrial Psychology. 2019; 45:1-12. https://doi.org/10.4102/ sajip.v45i0.1595.

3. Ghazvini K, Mohammadi A, Jalili M. The impact of the faculty development workshop on educational research abilities of faculties in Mashhad University of Medical Sciences. Future of Medical Education Journal. 2014; 4:24-27.

4. Sinclair J, Aho AM. Experts on super innovators: understanding staff adoption of learning management systems. Higher Education Research and Development. 2018; 37:158-172. https:// doi.org/10.1080/07294360.2017.1342609.

5. Haaranen A, Saarti J. Enthusiastic Academic and Support Service Staff as an Agent for Change: A Case Study Based on a Project in African Higher Education Institutes. Academic Conferences and Publishing International-ACPIL; 2020. https://doi.org/10.34190/ EJEL.20.18.1.001.

6. Dhungana GP, Piryani RM, Chapagain ML, et al. Effectiveness of teacher training conducted at Chitwan. Medical College, Bharatpur, Nepal. Journal of Chitwan Medical College. 2015; 5:15. https://doi.org/10.3126/jcmc.v5i2.13147.

7. Jones M, Schuer KM, Ballard JA, et al. Outcomes of an immersive pilot faculty development program for inter-professional facilitation: A mixed methods study. Journal of Inter-professional Education. 2015; 1:83-89. https://doi.org/10.1016/j. xjep.2015.10.001.

8. Bendermacher GW, De Grave WS, Wolfhagen IH, et al. Shaping a culture for continuous quality improvement in undergraduate medical education. Academic Medicine. 2020; 95. https:// doi.org/10.1097/ACM.0000000000003406. PMid: 32287081 PMCid:PMC7678663.

9. Cordero JM, Gil-Izquierdo M. The effect of teaching strategies on student achievement: An analysis using TALIS-PISA-link. Journal of Policy Modeling. 2018; 40:1313-1331. https://doi. org/10.1016/j.jpolmod.2018.04.003.

10. Brinkley-Etzkorn KE. Learning to teach online: Measuring the influence of faculty development training on teaching effective- 
ness through a TPACK lens. The Internet and Higher Education. 2018; 38:28-35. https://doi.org/10.1016/j.iheduc.2018.04.004.

11. Sarikaya $O$, Kalaca $S$, Yeğen BÇ, et al. The impact of a faculty development program: Evaluation based on the self-assessment of medical educators from preclinical and clinical disciplines. Advances in Physiology Education. 2010; 34:35-40. https://doi. org/10.1152/advan.00024.2010. PMid 20522894.

12. Muammar OM, Alkathiri MS. What really matters to faculty members attending professional development programs in higher education. International Journal for Academic Development. 2021; 1-13. https://doi.org/10.1080/1360144X.2021.1897987.

13. Steinert Y, Mann K, Anderson B, et al. A systematic review of faculty development initiatives designed to enhance teaching effectiveness: A 10-year update. BEME Guide No. 2016; 38:769786. https://doi.org/10.1080/0142159X.2016.1181851. PMid: 27420193.

14. Kamel AM. Role of faculty development programs in improving teaching and learning. Saudi Journal of Oral Sciences. 2016; 3:61. https://doi.org/10.4103/1658-6816.188073.

15. Almannie M. Barriers encountered in the transfer of educational training to workplace practice in Saudi Arabia. Journal of Education and Training Studies. 2015; 3:10-17. https://doi. org/10.11114/jets.v3i5.905.

16. Fabriz S, Hansen M, Heckmann C, et al. How a professional development programme for university teachers impacts their teaching-related self-efficacy, self-concept, and subjective knowl- edge. Higher Education Research and Development. 2021; 40:738-752. https://doi.org/10.1080/07294360.2020.1787957.

17. Guraya SY, Chen S. The impact and effectiveness of faculty development program in fostering the faculty's knowledge, skills, and professional competence: a systematic review and meta-analysis. Saudi Journal of Biological Sciences. 2019; 26:688-697. https:// doi.org/10.1016/j.sjbs.2017.10.024. PMid: 31048993 PMCid: PMC6486500.

18. Zheng M, Bender D, Nadershahi N. Faculty professional development in emergent pedagogies for instructional innovation in dental education. European Journal of Dental Education. 2017; 21:67-78. https://doi.org/10.1111/eje.12180. PMid: 26663694.

19. Moriates C, Valencia V, Stamets S, et al. Using interactive learning modules to teach value-based health care to health professions trainees across the United States. Academic Medicine. 2019; 94:1332. https://doi.org/10.1097/ACM.0000000000002670. PMid:31460928 PMCid:PMC6727932.

20. Edwards RA, Venugopal S, Navedo D, et al. Addressing needs of diverse stakeholders: Twelve tips for leaders of health professions education programs. Medical Teacher. 2019; 41:17-23. https:// doi.org/10.1080/0142159X.2017.1396307. PMid: 29141475.

21. Smidt A, Balandin S, Sigafoos J, et al. The Kirkpatrick model: A useful tool for evaluating training outcomes. Journal of Intellectual and Developmental Disability. 2009; 34:266-274. https://doi.org/10.1080/13668250903093125. PMid: 19681007. 